\title{
Physiochemical properties and fatty acid profile of grapes available in Peshawar city
}

\author{
Ata Ullah ${ }^{1 *}$, Azmat Ali Awan' ${ }^{2}$ Tasbeeh Ullah ${ }^{1}$, Ijaz Ahmad ${ }^{3}$, \\ Muhammad Muneeb ${ }^{4}$, Neelam Manzoor ${ }^{1}$, Salah Uddin ${ }^{3}$ and Ajmeel Ur \\ Rahman $^{1}$ \\ 1. Department of Agricultural Chemistry, The University Agriculture Peshawar-Pakistan \\ 2. Pakistan Oilseed Development Board Peshawar-Pakistan \\ 3. Department of Human Nutrition, The University Agriculture Peshawar-Pakistan \\ 4. Department of food science and technology, The University Agriculture Peshawar-Pakistan \\ *Corresponding author's email: hamdard4naz@yahoo.com; attabjr821@gmail.com \\ Citation \\ Ata Ullah, Azmat Ali Awan, Tasbeeh Ullah, Ijaz Ahmad, Muhammad Muneeb, Neelam Manzoor, Salah Uddin and \\ Ajmeel Ur Rahman. Physiochemical properties and fatty acid profile of grapes available in Peshawar city. Pure and \\ Applied Biology. Vol. 7, Issue 1, pp248-254. http://dx.doi.org/10.19045/bspab.2018.70030
}

\begin{tabular}{llll}
\hline \hline Received: 27/11/2017 & Revised: 31/01/2018 & Accepted: 09/02/2018 & Online First: 15/02/2018
\end{tabular}

\section{Abstract}

Various types of grapes (Large blue-red, large red, Sunder Khani, middle-sized green, and small yellow) grapes were collected from the local fruits markets of Peshawar City in September 2016 season. The samples were examined for their physicochemical parameters and fatty acid profile. The data showed that $p H$ of all types of grapes was in acidic region i.e. below 7. Higher (26.0) TSS value was recorded for the small yellow type of grapes. Very slight difference was found among the acids values of the analyzed samples of grapes with range of 6 to 7 . Sugar ranged from 50 to $75 \%$ with the maximum amount seen in large blue red grapes. The berries contained considerable amount of moisture (75.43 to $92.34 \%$ ) in all samples with maximum amount seen in large blue-red. $\mathrm{Na}$ and $\mathrm{K}$ were also present in appreciable amounts. Na was high in Sunder khani while the maximum amount of $\mathrm{K}$ was seen in large blue red types of grapes. Fatty acid profile i.e. (palmitic, stearic, linoleic, arachidic, palmitoleic and oleic) was investigated by GC gaschromatography. Linoleic acid, was found the most abundant acid in fatty acid profile ranging from $66.5 \%$ to $73.2 \%$ in small yellow grapes. Considerable amount of oleic acid was also present in all samples. The acidic $p H$, inclusion of $\mathrm{K}$ and appropriate amount of moisture made the grapes very attractive fruits that should be studied for other beneficial constituents.

Keywords: Acid value; Fatty acid profile; Grapes; Linoleic acid; Moisture

\section{Introduction}

Grapes (Vitis vinifera) are botanically true berries, grow as vine trees. Originally "grape" meant bunch. Grapes berries are exceedingly delicious and attractive with variable tastes and colors. They are eaten mostly as whole fruits; however they are also utilized in preparation of numerous food products and the seeds of seeded varieties are used in medicine, predominantly antimicrobial drugs and nematicides [1]. 
Grapes cultivation dates back to 5000 B.C; however, the wide spread propagation of grapes was started in Europe, and then spread to Australia, America and other countries through invaders and sailors. Egyptians used the grapes for wine, and later the technology was developed in various western countries, particularly Spain, France and Germany. Grapes consist mainly of two groups, one contains seeds while the others are seedless. The seedlessness is a highly desirable quality of the grape. Among these seedless types some are natural and some are genetically obtained from basic seedless varietals which all belong to basic types of Vitis group. The seedless types are very easy in eating but some of the basic quality of seeds are not present in these grapes [2].

Grape seeds contain various phytochemicals, which help in anti-oxidation. Anti-oxidant, increase hormone production, keep skin fair, and also help the body's defense system. The polyphenols present in grapes aid in blood pressure regulation and production and protection of epithial cells. They also help fight cancer and minimize the risk of heart failure. They reduce muscular dystrophy [3]. The oil extracted from grape seeds are used in many health care products like cosmetics. These oils also contain vitamin E, a polyunsaturated fatty acid of n-3, n-6, and n9 series, which protects the body from free radical attacks [4]. Like grapes, grape juice also helps fight in cancer, reduces risk of heart attack, improves brain health, and enables the body to with stand aging problems with the passage of time. Grape juice normalize the hypertension problems [5].

A good understand of grape composition is essential to understand its nutritional and medicinal benefits in detail. The present research aimed to study some of the physical and compositional parameters of locally available grapes in the markets.

\section{Materials and methods}

Local grape types were studied for their nutritional composition in the Department of Agricultural Chemistry, The University of Agriculture Peshawar (UAP) in September 2016.

\section{Samples}

Large blue-red, large red, Sunder Khani, middle-sized green, and small were obtained from local markets of Peshawar city. The grapes berries were removed from their clusters and cleaned and washed with warm water. The juices were extracted by breaking and pressing in doubly folded malmal cloth. The juice was immediately tested for various physical and chemical parameters.

\section{pH}

$P H$ of the selected samples was determined using $\mathrm{pH}$ meter. The $\mathrm{pH}$ meter was turned on and calibrated by a two; point calibration method using pH 4 and 7 buffer solutions [6]. The juice samples were tested for their $\mathrm{pH}$ by inserting the $p H$ electrode. After each iteration the electrode was washed with double distilled water.

\section{Total Soluble Solids (TSS)}

The TSS was analyzed by Abbes refractometer [6] prior to operation, the temperature was brought close to room temperature. A drop of sample was placed on the fixed prism and covered by the movable prism fixed in the lid. Then the knobs were rotated until the critical ray came at the center of the cross made inside the refractometer in the upper colored field. The data was recorded in degree Brix from the lower field where refractive index and degree brix scales were present.

\section{Acid value}

The samples were analyzed for acid value [6] $5 \mathrm{ml}$ of sample and $50 \mathrm{ml} 2 \mathrm{~N}$ Ethanol were mixed in a conical flask and, kept in a water bath for 30 minutes. After cooling two drops of phenolphthalein were added. The mixtures were then titrated against $0.1 \mathrm{~N} \mathrm{KOH}$ until 
pink colour appeared. The acid value was calculated from the $\mathrm{KOH}$ consumed.

\section{Sugar content}

The samples were analyzed for sugar content through the [7] method. For determination of sugar content, $5 \mathrm{ml}$ Fehling $A$ and $5 \mathrm{~mL}$ Fehling B were mixed in conical flasks and $20 \mathrm{~mL}$ of distilled water added. The juice was taken in burette, and titration was carried out till the brick-red color appeared in boiling mixtures of Fehling solutions. The titration reading was noted, and reducing sugar was calculated using the factor, where $\mathrm{Cu}$ content in $5 \mathrm{~mL}$ Fehling $\mathrm{A}+5 \mathrm{~mL}$ of Fehling $\mathrm{B}$ is sufficient to be reduced by $0.05 \mathrm{~g}$ of reducing sugar in the samples.

\section{Moisture}

Moisture content was detected from the weight loss of the samples by heating [8]. The empty Petri dish was cleaned and weighed. Samples were deposited and again weight was taken. The sample weight was obtained by subtracting the empty weight of the Petri dish. The samples were placed in a $105{ }^{\circ} \mathrm{C}$ oven for several hours in a Petri dish with half closed lid. The dish was then covered with the lid and placed in a dissector for cooling. The weight was noted and the percent loss in weight was taken as moisture.

\section{Mineral analysis}

\section{Preparation of acid digest:}

The sample was digested with acid following the standard method of [6] Sample (1 ml) was weighed and poured it into a digestion flask and mixed with $5 \mathrm{~mL}$ of $\mathrm{HNO} 3$ and per chloric acid and then heated slowly and gradually up to $300{ }^{\circ} \mathrm{C}$. When white fumes were exhausted, $5 \mathrm{ml}$ per chloric acid were added again until the white fumes vanished. The one $\mathrm{ml}$ residue remaining was diluted with distilled water to $50 \mathrm{ml}$ which then was used for mineral analysis.

\section{Determination of $\mathrm{Na}$ and $\mathrm{K}$}

$\mathrm{Na}$ and $\mathrm{K}$ were determined by flame photometer [7]. The flame photometer measured the emitted light from the excitation of atomic specie. Standard solutions of $\mathrm{NaCl}$ and $\mathrm{KCl}$ was prepared in ppm level. The working standards of $\mathrm{Na}$ and $\mathrm{K}$ were prepared in the range of 0.1 to 50 ppm. Flame photometer was used and where the reading of each five standards working solutions for $\mathrm{Na} \mathrm{K}$ was recorded. These values were used for standard curve formation with, the $\mathrm{x}$-axis as concentration of $\mathrm{Na}$ and $\mathrm{K}$ and the $\mathrm{y}$-axis was used for excitation reading. The sample digest was taken and their excitation reading were noted then compared with their respective curves and real concentration was calculated for $\mathrm{Na}$ and $\mathrm{K}$ content in the samples.

\section{Fatty acid profile}

Method were used for preparation of Fatty acid methyl esters (FAMEs) [9]. One mg of oil was mixed with $0.1 \mathrm{M} \mathrm{NaOHAMeOH}$ for 5 min. HClAMeOH 4\% was added to the mixture and steered for $5 \mathrm{~min}$, at ambient temperature. The reaction was stopped by adding water Fatty acid methyl ester (FAMES) were extracted with iso-octane. Shimadzu GC-2010 equipped, with a FID and a (Shimadzu, Columbia, MD) autosampler were used for GC analysis. A fused silica capillary column SPTM -2380 (30 $\mathrm{m} \_0.25 \mathrm{~mm}$ with a $0.25 \mathrm{~lm}$ film thickness) silica capillary was used as column. Helium a carrier gas was used at a flow rate of 0.8 $\mathrm{ml} / \mathrm{min}$.

Individual FAMEs retention time were compared with retention time of standard of FAMEs for the identification of each component of fatty acid profile.

All samples were analyzed in triplicate.

\section{Results and discussion}

Various grape types Big \& blue red, Red \& bigger size, Sunder khani, Middle size green, Small \& yellow were analyzed for physiochemical parameters i.e., $p H$, TSS, acid value, sugar content moisture, mineral analysis fatty acid composition . 
pH

The data for mean $\mathrm{pH}$ of the five selected types of grape been presented in table 1 . Highest mean $\mathrm{pH}$ value (6.1) had been observed for large \& blue red grapes followed by sunder khani (5.25). Lowest mean $\mathrm{pH}$ value (4.8) was found for small $\&$ yellow grape sample. The result of the Table 1. $p H$ TSS (Brix ${ }^{\circ}$ Acid value, Sugar content (\%) of different grapes type available in local markets of Peshawar

\begin{tabular}{|c|c|c|c|c|}
\hline Name of sample & pH & TSS & Acid value & Sugar (\%) \\
\hline Large blue-red & 5.00 & 23.2 & 7.05 & 75 \\
\hline Large red & 6.10 & 22.1 & 7.95 & 50 \\
\hline Sunder khani & 5.25 & 22.0 & 7.28 & 70 \\
\hline Middle-sized green & 5.20 & 16.0 & 7.72 & 73 \\
\hline Small \& yellow & 4.10 & 26.0 & 6.38 & 65 \\
\hline
\end{tabular}

\section{Total soluble solid (TSS)}

The data presented in table 1 show the TSS values for the five selected samples of grapes which was ranged from 22 to $26^{\circ}$ brix. Highest mean TSS value (26 ${ }^{\circ}$ brix) had been observed for small \& yellow grapes followed by large blue-red (23.2 ${ }^{\circ}$ brix) grapes. Lowest mean TSS value (16 ${ }^{\circ}$ brix) was found for middle-sized green grape sample. Our finding for TSS content of grape was strongly supported by the work done by [11].

Acid value and sugar content

The date for acid value and sugar content is also depicted in table 1. Highest mean acid value $(7.95 \%)$ was noticed for large red grape, while Small \& yellow grape had lowest $(6.38 \%)$ mean acid value. Large blue- present study were in fair agreement with finding of [10], who worked on the composition of grape types. The $p H$ difference might be due to the tartaric acid content of the grape types because this is the main acid in grapes. However other reasons like high or low TSS might also be another cause of difference in $\mathrm{pH}$ level. red contained high sugar content $(75 \%)$ while the least sugar content was found in Small \& yellow $(65 \%)$. The data agrees with work done by [12].

\section{Moisture content}

The results depicted in table 2 shows the average moisture content in the fruits of grapes cultivars which is ranged from $75.43 \%$ to $92.34 \%$. The difference among the different types with respect to moisture content was significant. Maximum moisture content was found in large blue-red $92.34 \%$ while the least moisture content was found in middle-sized green grapes (75.43). The results of the present study go parallel to the finding of [13].

Table 2. Moisture (\%) of various grape types available in local Markets of Peshawar

\begin{tabular}{|c|c|}
\hline Name of Sample & Moisture \% \\
\hline Large blue-red & 92.34 \\
\hline Large red & 78.33 \\
\hline Sunder khani & 79.65 \\
\hline Middle-sized green & 75.43 \\
\hline Small \& yellow & 76.18 \\
\hline
\end{tabular}

\section{Mineral (Na, K)}

Significant (0.005) results were obtained for $\mathrm{Na}, \mathrm{K}$ as shown in table (Table 3). Highest 
sized green $(1.80 \mathrm{mg} / \mathrm{Kg})$. Similarly, maximum $\mathrm{K}$ was found in large blue red (165 $\mathrm{mg} / \mathrm{Kg}$ ) followed by Sunder $164 \mathrm{mg} / \mathrm{Kg}$, while, the minimum was obtained in Middle-

\section{Table 3. Na and $\mathrm{K}(\mathrm{mg} / \mathrm{Kg})$ of grapes types a}

Table 3. Na and K $(\mathbf{m g} / \mathbf{K g})$ of grapes types available in the local Markets of Peshawar
\begin{tabular}{|c|c|c|}
\hline Name of Sample & Sodium & Potassium \\
\hline Large blue red & 2.60 & 165 \\
\hline Large red & 3.43 & 163 \\
\hline Sunder khani & 4.26 & 164 \\
\hline Middle-size green & 1.80 & 159 \\
\hline Small \& yellow & 3.60 & 160 \\
\hline
\end{tabular}

\section{Fatty acid composition}

The qualitative assessment of grapes is directly related to the composition of the fatty acid. The nutritional implications and oxidative stability of oils are related to the sized green $(159 \mathrm{mg} / \mathrm{Kg})$. The data of the present study was supported by [13] who studied grapes cultivars for their nutritional composition.

Table 4. Fatty acid profile of olive oils samples (\%)

\begin{tabular}{|c|c|c|c|c|c|c|c|}
\hline Sample & $\mathbf{1 6 : 0}$ & $\mathbf{2 0 : 1}$ & $\mathbf{1 8 : 1}$ & $\mathbf{1 8 : 2}$ & $\mathbf{1 8 : 3}$ & $\mathbf{1 8 : 0}$ & $\mathbf{2 0 : 0}$ \\
\hline Large blue red & 8.99 & 1.47 & 21.5 & 65.3 & 1.03 & 2.24 & 0.14 \\
\hline Sunder khani & 6.50 & 0.94 & 14.2 & 70.5 & 0.61 & 4.1 & 056 \\
\hline Large red & 7.771 & 1.04 & 12.3 & 67.8 & 0.88 & 2.65 & 0.13 \\
\hline Middle-sized green & 5.55 & 0.35 & 17.07 & 74.9 & 0.34 & 3.33 & 0.46 \\
\hline Small \& yellow & 6.81 & 0.8 & 19.09 & 73.2 & 0.76 & 2.6 & 021 \\
\hline
\end{tabular}

Linoleic acid was the most abundant fatty acid in all five cold pressed grape seed oils, with range of $65.3 \%$ and $73.2 \%$ of total fatty acids (Figure 1).

Content of linoleic acid (73.2\%) was found at highest amount in small and yellow oil seed with large red containing the lowest amount of $65.3 \%$.

Amounts of oleic acid, was also present in significant amount ranging from $12.3 \%$ unsaturated fatty acid (UFA). The five selected samples were analyzed by gas chromatography for fatty acid compositions and the result are inserted in table 4. (large red) to $21.5 \%$ (Big \& blue red). Other fatty acids present include stearic acid (2$4 \%$ ).

The reported results were quite similar in the literature $[14,15]$. The linoleic acid was found in range of $66.8-73.6 \%$ in the seed oils of seven different varieties of grapes by [16]. Higher or lower values, depending on seed origin and method of oil extraction were reported by some other authors [17]. 


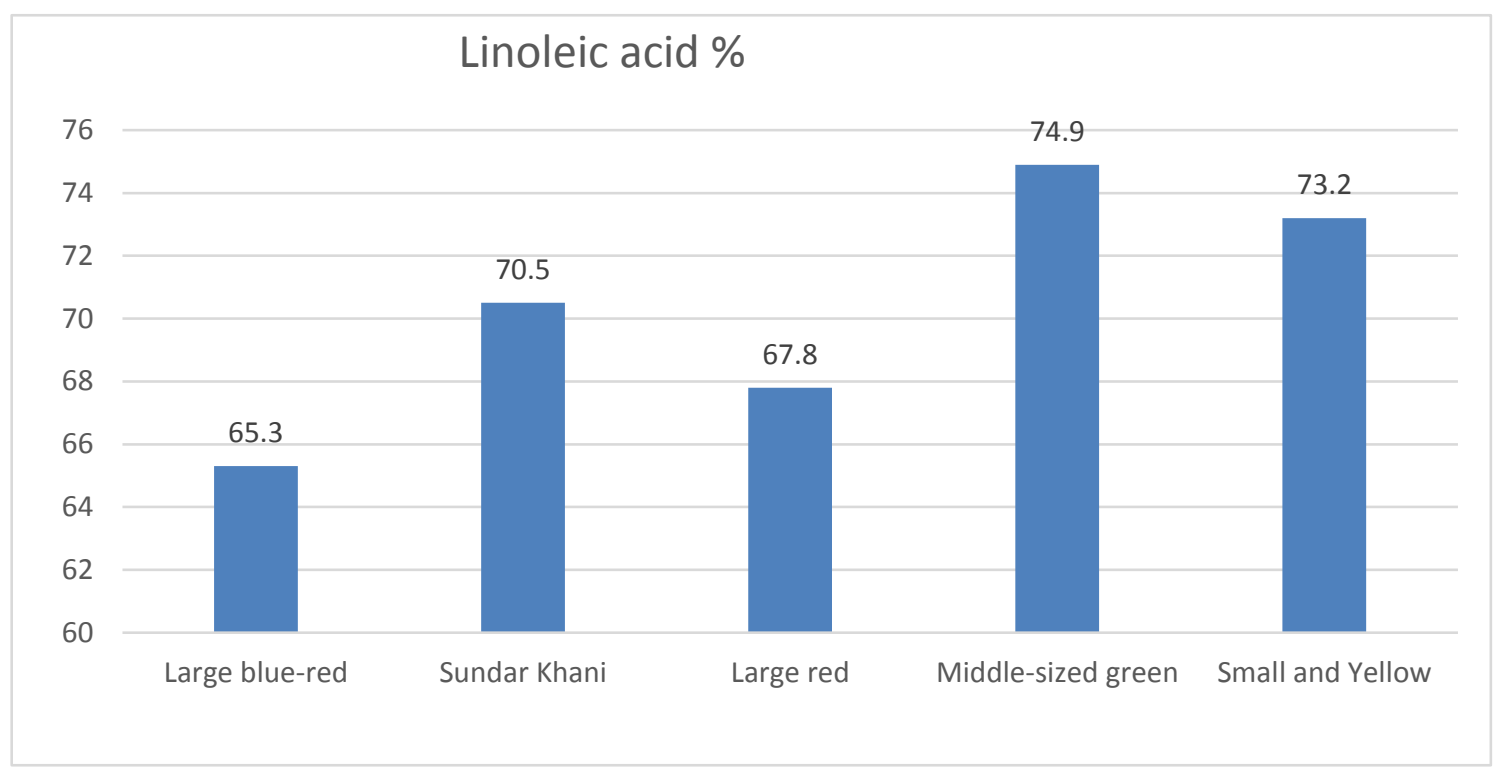

Figure 1. Percentage of Linoleic acid

\section{Conclusion}

$\mathrm{PH}$ of the grapes was in acidic in nature. TSS of the grapes types was variable some contained comparatively small amount and some contained considerably large amount. Sugar content of the types was also variable and the large size berries contained high amount of sugar. Grapes contained a large amount of moisture, so this is very succulent berries which can fulfill the water need of the body to some extent. All types of grapes were also a good source of $\mathrm{Na}$ and $\mathrm{K}$. Linoleic acid, was found the most abundant acid in fatty acid profile ranging from $66.5 \%$ to $73.2 \%$ in small yellow grapes. Considerable amount of oleic acid was also present in all samples.

\section{Recommendation}

The valuable compounds of grapes should be analyzed in a scientific way to highlight their usefulness.

\section{Authors' contributions}

Conceived and designed the experiments: A Ullah \& AA Awan. Performed the experiments: A Ullah \& T Ullah, Analyzed the data: A Ullah \& I Ahmad, Contributed materials/ analysis/ tools: M Muneeb \& N Manzoor, Wrote the paper: A Ullah, S Uddin \& AU Rahman.

\section{Acknowledgments}

We Acknowledge Dr. Saleem Ullah the chairman of the department of Agricultural Chemistry, The University of Agriculture Peshawar, Pakistan for permission to labs and instruments for experiments.

\section{References.}

1. Shankar S, Singh G \& Srivastava RKS (2007). Chemoprevention by restroval: molecular mechanisims and therapeutic potential. Front Biosci 12(12): 4839- 54.

2. Mancuso C, Bates TE, Butterfield DA, Calafato S, Cornelius C, Lorenzo AD, \& Calabrese V (2007). Natural antioxidants in Alzheimer's disease. Expert opinion on investigational drugs 16(12): 1921-1931.

3. Opie LH \& Lecour S (2007). The red wine hypothesis: from concepts to protective signalling molecules. European heart J 28(14): 1683-1693.

4. De-Berardinis RJ, Mancuso A, Daikhin E, Nissim I, Yudkoff M, Wehrli S \& Thompson CB (2007). Beyond aerobic glycolysis: transformed cells can engage in glutamine metabolism that exceeds the requirement for protein and nucleotide synthesis. Proceedings of the National 
Academy of Sciences 104(49): 1934519350.

5. Jung KJ, Wallig MA, \& Singletary KW (2006). Purple grape juice inhibits 7, 12dimethylbenz [a] anthracene (DMBA)induced rat mammary tumorigenesis and in vivo DMBA-DNA adduct formation. Cancer letters 233(2): 279288.

6. A.O.A.C (Association of official analytical chemistry) 2000 official methods of analysis (Ed. Helrich, K.) 15th edition.Arlington, Virginia.USA.

7. Khalil IA \& Manan F (1990). Chemistryone (Bio-analytical chemistry).

8. Khalil IA \& Saleemullah (2004). Bioanalytical chemistry, P.26-29. National Book Foundation, Islamabad, Pakistan P 29.

9. Parry J, Hao Z, Luther M, Su L, Zhou K \& Yu LL (2006). Characterization of cold-pressed onion, parsley, cardamom, mullein, roasted pumpkin, and milk thistle seed oils. $J$ of the American Oil Chemists' Society 83(10): 847-854.

10. Robertson G. L, \& Nisperos MO (1983). Changes in the chemical constituents of New Zealand grapefruit during maturation. Food Chemistry 11(3): 167174.

11. Rhodes P L, Mitchell JW, Wilson MW \& Melton LD (2006). Antilisterial activity of grape juice and grape extracts derived from Vitis vinifera variety Ribier. International $J$ of food Microbiology 107(3): 281-286.
12. Kamel BS, Dawson H, \& Kakuda Y (1985). Characteristics and composition of melon and grape seed oils and cakes. Journal of the American Oil Chemists' Society 62(5): 881-883.

13. Harel E \& Mayer AM (1971). Partial purification and properties of catechol oxidases in grapes. Phytochemistry 10(1): 17-22.

14. Jordão AM, Ricardo-da-Silva J M, \& Laureano O (2001). Evolution of catechins and oligomeric procyanidins during grape maturation of Castelão Francês and Touriga Francesa. American $J$ of Enology and Viticulture 52(3): 230234.

15. Crews C, Hough P, Godward J, Brereton P, Lees M, Guiet S, \& Winkelmann W (2006). Quantitation of the main constituents of some authentic grape-seed oils of different origin. $J$ of Agricultural and Food Chemistry 54(17): 6261-6265.

16. Beveridge $\mathrm{T} H$, Girard B, Kopp $\mathrm{T} \&$ Drover JC (2005). Yield and composition of grape seed oils extracted by supercritical carbon dioxide and petroleum ether: varietal effects. $J$ of Agricultural and Food Chemistry 53(5): 1799-1804.

17. El-Shami SM, El-Mallah MH \& Mohamed SS (1992). Studies on the lipid constituents of grape seeds recovered from pomace resulting from white grape processing. Grasas Y Aceites 43(3): 157160. 